\title{
Evaluación de la actividad celulolítica y quitinolítica de hongos filamentosos aislados de rizósfera de cultivos de papa para control de rhizoctonia solani
}

\author{
Evaluation of the cellulolytic and chitinolytic activity of rhizosphere \\ isolated filamentous fungi from potato cultures to control rhizoctonia \\ solani
}

Campuzano F Silvia E ${ }^{1}$, Urquijo T Laura ${ }^{1}$, Valderrama Jessica ${ }^{1}$

\section{Resumen}

Objetivo. Evaluar la actividad celulolítica y quitinolítica de los hongos aislados de rizósfera de papa con posibilidades de ser usados para el control biológico de $R$. solani. Método. Se aislaron y clasificaron los hongos, mediante sus características macroscópicas y microscópicas. Se aplicaron pruebas para evaluar la capacidad celulolítica y quitinolítica de los hongos y se probó su capacidad antagónica frente al fitopatógeno. Se realizó análisis fisicoquímico del suelo del cual se aislaron los hongos de estudio. Resultado. Del total de hongos caracterizados, solamente una cepa de Rhizopus $s p$ determinada como TN8 fue la que presentó la mejor actividad antagónica frente a $R$. solani, lo cual, permite considerar este hongo como posible agente de biocontrol para el fitopatógeno de estudio.

Palabras claves: Control biológico, hongos celulíticos, hongos quitinolíticos, papa, plaga.

\section{Abstract}

Objective. To evaluate the cellulolytic and chitinolytic activity of fungi isolated from potato rhizosphere with possibilities of being used for the biological control of R. solani. Method. The fungi were isolated and classified by their macroscopic and microscopic characteristics. Tests were applied to evaluate the cellulolytic and chitinolytic capabilities of fungi and their antagonistic capabilities against the phytopathogen were tested. Physicochemical analysis of the soil from which the fungi were isolated were also performed. Result. From the total characterized fungi, only one strain of Rhizopus sp was determined as TN8 and this was the only one that presented the best antagonistic activity against $\mathrm{R}$. solani. This result lead us to consider that this fungus is a possible biocontrol agent for the phytopathogen of this study.

Keywords: Biological control, Cellulytic fungi, Chitinolytic fungi, Potato, Plague. 


\section{Introducción}

La papa constituye uno de los productos alimenticios de mayor importancia. En Latinoamérica, Colombia ocupa el cuarto puesto en producción, principalmente en Boyacá, Cundinamarca, Antioquia y Nariño. El cultivo de papa es afectado constantemente por diferentes plagas, que le ocasiona pérdidas alrededor del $6.5 \%$ de la producción.

Las pérdidas anuales de papa a nivel mundial oscilan en 93 millones de toneladas lo que equivale a 7.200 millones de dólares. En Colombia la pérdida es de 195 mil toneladas al año de papa por diferentes plagas, por lo que los agricultores se ven obligados a utilizar pesticidas para mitigar el daño causado por estos agentes patógenos. Muchos organismos crean resistencia a estos productos químicos, forzando a los agricultores a utilizar pesticidas con una actividad más tóxica y en mayor cantidad, lo cual repercute con la economía de ellos.

Por esta razón, se ha generado la necesidad de buscar alternativas biológicas que tengan efecto potencial sobre los microorganismos patógenos y plagas, sin afectar las poblaciones de microorganismos benéficos, minimizando así el impacto sobre el ambiente y la salud humana y es precisamente el control de riesgo biológico la oportunidad de evitar estos riesgos.

El control biológico contribuye a disminuir el deterioro ambiental y que su efectividad demuestre a los agricultores su potencialidad para disminuir el uso de agroquímicos, por lo cual, en el presente trabajo se aisló, identificó y evaluó la capacidad enzimática de hongos aislados de rizósfera de cultivo de papa de Cundinamarca y Boyacá, para determinar su papel como antagonistas frente a uno de los principales fitopatógenos $R$. solani, que afecta a Solanum tuberosum (papa pastusa) y Solanum phureja (papa criolla). Esas alternativas, pueden ofrecer un nuevo camino para el tratamiento de los cultivos incrementando la competitividad del sector agrícola de papa en Colombia, disminuir los altos costos de producción y el cumplimiento efectivo de medidas regulatorias de calidad, inocuidad y sostenibilidad que permitan una expansión del mercado nacional e internacional.

Para controlar el daño producido por hongos patógenos en diversos cultivos de interés agrícola, muchos estudios han enfocado sus esfuerzos en determinar la capacidad de los hongos como agentes biocontroladores y esta acción está directamente relacionada con la producción de enzimas extracelulares, como las quitinasas y celulasas que pueden dañar la pared celular del hongo patógeno.

La actividad de estas enzimas ha sido estudiada por Tovar et al. 2008, donde demostraron la eficiencia de enzimas quitinolíticas de 15 cepas de Trichoderma frente a fitopatógenos como $R$. solani, Rhizoctonia meloni y Botrytis cinérea. T. harzianum ha sido una de las especies de Trichoderma más estudiadas, y se ha determinado en esta especie la producción de enzimas $\mathrm{N}$-acetilglucosaminidasas, endoquitinasas, y quitobiosidasas, las cuales tienen funciones importantes en el control de fitopatógenos, la producción de quito-oligosacáridos y en la degradación de sustratos de quitina $(4,6)$, el 25$60 \%$ del total de los hongos filamentosos tienen esta capacidad quitinolítica lo que permite degradar la quitina tanto en condiciones aeróbicas como anaeróbicas (6).

El principal resultado del estudio se relaciona con la recuperación y aislamiento de la cepa TN8 de Rhizopus sp como la mejor opción antagónica contra $R$. solani, característica que lo propone como posible biocontrolador

\section{Metodología}

\section{Obtención de muestras de rizósfera y aislamien-}

to de cepas: Se recolectaron muestras de suelo de cultivo de papa de tres fincas, una ubicada en Sibaté (Cundinamarca) y dos ubicadas en Boyacá. La muestra fue constituida por un muestreo de cada finca y cada muestreo con tres réplicas. Las 
muestras de rizósfera de papa se maceraron para dejar libres los microorganismos endófitos. Posteriormente se realizó un enriquecimiento inicial de cada muestra utilizando $50 \mathrm{~mL}$ de medio mínimo con glucosa $2 \%$ como única fuente de carbono + $2 \mathrm{~g}$ de rizósfera macerada. Se agitaron durante ocho días a $200 \mathrm{rpm}$ a $28^{\circ} \mathrm{C}$. Posteriormente se realizaron siembras en placas de PDA en diluciones 1:60, 1:80 y 1:100; después de 2 días se realizó un repique de las colonias para aislar cada hongo individualmente. Se evaluaron de acuerdo a las características fenotípicas de cada colonia desde la valoración macroscópica y microscópica y su capacidad celulolítica y quinilolítica

\section{Identificación de género de los hongos aislados:} se realizó la caracterización macroscópica y microscópica, por medio de descripción morfológica de colonias en agar PDA y microcultivos para la identificación de acuerdo a características de las colonias y las estructuras microscópicas de acuerdo al método estándar de diagnóstico microbiológico de hongos. En el estudio solamente se tuvieron en cuenta los hongos filamentosos, cada cepa se identificó utilizando la primera letra de la finca donde fue aislada seguida de un número consecutivo.

Inducción de la producción de celulasas y quitinasas: Todos los hongos filamentosos aislados fueron sembrados en placas de medio mínimo sólido según el protocolo de Inglis en 2000, al cual se adicionó $2 \%$ de la fuente de carbono Carboximetilcelulosa (CMC) y/o quitina coloidal, las placas se incubaron durante ocho días a $28^{\circ} \mathrm{C}(3)$.

Se realizó una prueba para evidenciar la actividad celulolítica cualitativa de los hongos por medio del colorante rojo Congo según lo descrito por Teather (4).

La actividad celulolítica fue evaluada en medio mínimo con 2\% de CMC, en la cual fueron inoculadas las cepas, la actividad cualitativa fue positiva por la presencia de halos de hidrólisis al octavo día, observados al adicionar rojo Congo.
Determinación de halos de crecimiento en medios con CMC y quitina coloidal: Se midió el área de crecimiento de cada hongo en los dos medios usando el software Image de NHI.

En relación a la degradación de Carboximetilcelulosa en medio mínimo, se observa el diámetro de hidrólisis en medio mínimo con CMC observado al adicionar Rojo Congo.

Cálculo de la tasa de crecimiento: Se calculó la tasa de crecimiento de cada hongo sembrando alícuotas de $0.5 \mathrm{~cm}$ del hongo en placas de PDA y se midió el área de crecimiento durante tres días consecutivos. Se determinó el área de crecimiento por medio del uso del software ImageJ de NHI, se halló el diámetro según el área calculada y se utilizó la siguiente formula (5):

$$
T c=\frac{C f-C i}{T f-T i}
$$

Dónde:

Cf: Crecimiento diametral final expresado en $\mathrm{cm}$ Ci: Crecimiento diametral inicial (día uno) expresado en $\mathrm{cm}$

Tf: Tiempo final en el que termina el crecimiento fúngico

Ti: Tiempo inicial (día uno)

Prueba de antagonismo: Se realizó según el método descrito por Bell et al 1982, tomando inóculos del hongo antagónico de $0.5 \mathrm{~cm} 2$ a partir de cajas de PDA y se sembraron por triplicado en medio con PDA a $1 \mathrm{~cm}$ del borde de la caja. Posteriormente se sembró en días diferentes a $R$. solani, dependiendo de la tasa de crecimiento de cada hongo aislado, con el fin de que ni el hongo antagónico ni el patógeno tuvieran ventaja en cuanto al tiempo de crecimiento, para esto se tomaron inóculos de $R$. solani de $0.5 \mathrm{~cm} 2$ a partir de cajas de PDA y se sembró en el extremo opuesto al hongo anta- 
gónico. Estos se incubaron a $28^{\circ} \mathrm{C}$ y se realizaron mediciones del área tres días después de sembrar R. solani.

Se usaron como controles Trichoderma sp (cepa productora de celulasas) y Beauveria sp (cepa productora de quitinasas) .

Posteriormente se determinó el área de crecimiento de $R$. solani y del hongo antagónico por medio del uso del software ImageJ de NHI, se realizó la conversión del área a diámetro utilizando la fórmula para hallar el porcentaje de inhibición micelial (5):

$$
\% I M=\frac{C M L-C M I}{C M L}
$$

Dónde:

$\mathrm{CML}=$ Diámetro del crecimiento micelial libre en $\mathrm{cm}$

CMI = Diámetro del crecimiento micelial influenciado en $\mathrm{cm}$

\%IM = Porcentaje de inhibición micelial
Estadística: Se realizó un análisis estadístico con el programa Statgraphic. Se realizó ANOVA para determinar diferencias entre tratamientos. A los datos se les evaluó la distribución normal por medio del test de Shapiro-Wilk, para homogeneidad de varianza; se usaron las pruebas estadísticas Levene y Bartlett. Los ensayos que no cumplieron los supuestos de ANOVA fueron transformados o evaluados mediante estadística no paramétrica (Prueba de Kruskal Wallis). Las medias fueron comparadas mediante la prueba de comparación múltiple LSD (diferencias mínimas significativas). Los resultados mostrados son de las cepas que cumplen con los criterios estadísticos.

\section{Resultados y discusión}

\section{Aislamiento de hongos presentes en rizósfera de papa de las tres fincas}

Tabla 1. Número y porcentaje de los diferentes géneros de hongos filamentosos aislados de rizósfera de papa de tres fincas ubicadas en Cundinamarca y Boyacá.

\begin{tabular}{|l|r|r|r|r|r|r|r|r|}
\hline \multicolumn{1}{|c|}{ Finca } & $\begin{array}{r}\text { Géneros de hongos filamentosos aislados } \\
\text { aislamientos }\end{array}$ & Aspergillus sp & Conidiobolus sp & Fusarium sp & Geotrichum sp & Mucor sp & Penicillium sp & Rhizopus sp \\
\hline Cerezo & 16 & & 3 & 6 & & & 7 & \\
\hline Sibaté & 11 & 3 & & & & & & \\
\hline Tapias Negras & 9 & 5 & & & & & 1 & \\
\hline Total & 36 & 8 & 3 & 6 & 4 & 1 & \\
\hline
\end{tabular}

En este estudio se observa que las fincas donde se logró aislar Aspergillus y Rhizopus no se aisló Penicillium, estos datos difieren de aquellos obtenidos por Ulacio, se aisló principalmente Penicillium $s p$ de rizósfera de papa, seguido por Aspergillus sp y Rhizopus sp. En estudios realizados por Arias et al en el 2008 se aislaron hongos filamentosos del páramo de Guasca y Cruz Verde de Cundinamarca, obteniendo mayor incidencia de Penicillium sp y As- pergillus sp. Los mismos resultados se observaron en estudios realizados por Mayea y colaboradores en 1991 donde aislaron hongos de rizósfera de papa. En general, se ha observado que Penicillium se logra aislar en suelos con temperaturas más frías y Aspergillus en suelos con piso térmico tropical sin embargo, la finca donde se aisló Penicillium (Cerezo) pertenece a la misma área de la finca Tapias Negras, en la cual no se logró aislar este hongo $(6)(7)(8)$. 
En estudios realizados por Fernández Linares se determinó que la cantidad de géneros y actividades de los microorganismos aislados de un suelo difiere mucho de un suelo a otro ya que esto se ve influenciado por las condiciones físico químicas propias de cada suelo, temperatura, disponibilidad de agua, oxígeno y nutrientes, técnicas de manejo de cada suelo y presencia de crecimiento de plantas (9).

Estos hallazgos están en relación con los mencionados por López, donde determinan que la microflora en suelos de tomate y toloache, presenta diferencias en cuanto a los géneros y su proporción debido a las condiciones físico químicas del mismo (10). Otros estudios sobre aislamiento y caracterización de hongos son mostrados por Vieira, donde aislaron hongos de rizósfera de pimiento negro, y los géneros que predominaron fueron Penicillium, Paecilomyces y Aspergillus lo que demuestra que los géneros de hongos pueden diferir de un suelo a otro (11), pero que de igual manera se correlacionan con los géneros predominantes obtenidos en nuestro estudio para Aspergillus y Penicillium.

En estudios realizados por Pérez, Conidiobolus sp es descrito como un hongo ampliamente aislado en suelo, también se ha descrito como patógeno de varias especies de insectos y causa patologías en humanos (12). Conidiobolus sp fue aislado únicamente en la finca El Cerezo, representó el 8,33\% del total de los aislamientos, seguido por Mucor sp con un $2,77 \%$ de aislamientos, el cual fue aislado únicamente en la finca Tapias Negras.

Fusarium es un hongo ampliamente descrito como fitopatógeno y no se ha demostrado su actividad biocontroladora (10), en el presente estudio se logró aislar este hongo en la finca Cerezo en el $37,5 \%$ de aislamientos en esta área, lo cual podría indicar un posible problema de fitopatógeno para el cultivo de papa de esta finca.

Geotrichum sp es un hongo saprofito causante de la llamada "pudrición ácida". Este hongo puede ser controlado por especies de hongos saprófitos como Penicillium, Cladosporium y Rhizopus en duraznos en postcosecha, de acuerdo a los estudios realizados por Castelleti. En el presente estudio este hongo levaduriforme fue aislado únicamente de la finca Sibaté donde tampoco se aisló Penicillium sp, lo cual puede sugerir que su permanencia puede estar más favorecida por Aspergillus y Rhizopus, y no por Penicillium (13).

Mucor es un hongo ampliamente descrito por encontrarse normalmente en la naturaleza. Diferentes autores lo han aislarlo de rizósfera de diferentes plantas, también se ha aislado de suelos contaminados con hidrocarburos y ha sido utilizado como sustrato para participar en acciones de biorremediación, por lo que estas cepas pueden ser evaluadas para esas actividades (14).

En estudios realizados por Rojas se encontró a Trichoderma como uno de los principales agentes fúngicos encontrados en suelos agrícolas, sin embargo, en este estudio no se aisló ninguna cepa de este hongo (6).

Todos los hongos filamentosos aislados fueron evaluados por su actividad celulolítica, quitinolíticas y de antagonismo frente a $R$. solani. Posteriormente se realizó un análisis de varianza ANOVA, donde fueron eliminadas algunas cepas por no cumplir con la homogeneidad de datos requerida por el software, se muestran las cepas que cumplieron los requerimientos para los tres análisis.

\section{Actividad celulolítica}

La actividad cualitativa fue positiva por la presencia de halos de hidrólisis al octavo día, observados al adicionar rojo Congo, se midieron las áreas de los halos y fueron analizados por un análisis de varianza ANOVA.

En general todas las cepas aisladas mostraron actividad celulolítica. En la Gráfica 1 se observa que algunas cepas como Conidiobolus sp (C11), Fusarium sp (C14), Rhizopus sp (S6), Rhizopus sp (S14), 
Aspergillus sp (TN1), Rhizopus sp (TN8), Rhizopus $s p$ (TN9), presentaron mayores halos de actividad sobre Carboximetilcelulosa, comparado incluso con el control de Trichoderma sp (T) y $R$. solani (RS).

Se puede notar que la finca Tapias Negras presentó el mayor número de cepas con actividad celulolítica representativa (tres cepas) sin embargo, en la finca Cerezo se lograron aislar dos cepas que presentan actividad celulolítica más alta.

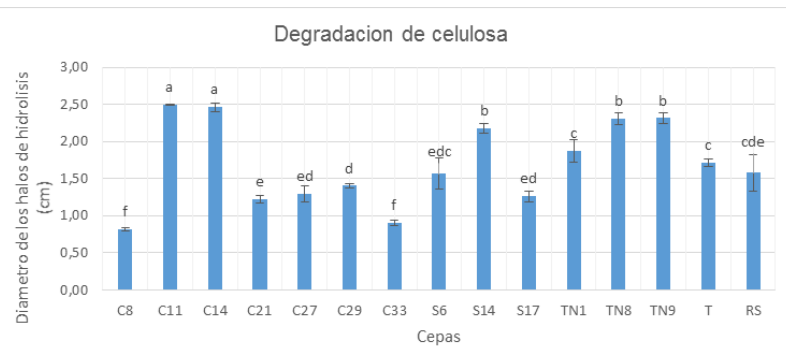

Gráfica 1. Degradación de Carboximetilcelulosa en medio mínimo, en el eje Y se observa el diámetro de hidrólisis en medio mínimo con CMC observado al adicionar Rojo Congo, en el eje X se observan las cepas, el control Trichoderma (T) y el fitopatógeno Rhizoctonia solani (RS).

Sáenz y colaboradores, hallaron hongos celulolíticos en rizósfera de papa, estos hongos fueron evaluados por su capacidad de crecer en medio mínimo con CMC como única fuente de carbono, se halló predominio el género Penicillium, seguido por Aspergillus, Trichoderma, Verticillium, Fusarium, Mucor y Botrytis (15), en el presente estudio de los hongos anteriormente nombrados se logró aislar Penicillium, Aspergillus, Fusarium, Mucor; los cuales también presentaron actividad celulolítica.

El género Conidiobolus sp no ha sido muy estudiado por su actividad celulolítica, ya que sus principales mecanismos son la proteólisis, sin embargo, en este estudio presentó el mayor diámetro de crecimiento en medio con Carboximetilcelulosa siendo la media de $2,49 \mathrm{~cm}$.

En estudios realizados por Giraldo y los presentados por Valencia se evidenció la actividad celulolítica de diferentes cepas de Fusarium sp. Este hongo ha sido reportado como un hongo con actividad celulolítica, lo cual le permite establecerse en la superficie de la planta, ocasionando ablandamiento por la desintegración de los componentes de la pared celular, y así permite la penetración y propagación del patógeno en los tejidos de su hospedero causando el colapso y desintegración de su estructura celular $(16,17)$. En el presente estudio se aislaron 6 cepas de Fusarium sp representando un 16,66\% del total de los aislamientos. Su proporción es un poco menor comparada con Penicillium, pero que debe ser considerado, debido a que Fusarium sp es agente causal de muchas enfermedades en plantas.

En este estudio se observó que Aspergillus (TN1) presentó un área de crecimiento de $1,87 \mathrm{~cm} 2$, en comparación con la cepa de Trichoderma, la cual presentó una media de $1,72 \mathrm{~cm} 2$, lo cual es compatible con los resultados realizados por Manjarrez donde se comparó la capacidad celulolítica de $A s$ pergillus sp frente a Trichoderma $s p$ en medios con CMC, y observaron una mayor actividad celulolítica por parte de Aspergillus, ambos hongos presentaron su máxima actividad celulolítica al séptimo día (18). Sin embargo, en este estudio las diferencias no son significativas. Aspergillus es un hongo ampliamente descrito por su actividad celulolítica, como ha sido demostrado por Cruz a partir de compost de hortalizas (19).

Así mismo en este estudio, se obtuvo actividad celulolítica de cuatro cepas de Rhizopus, en estudios realizados por Escobar y colaboradores (20), se logró aislar diferentes cepas de Rhizopus en compost por lo que puede pensarse que este realiza actividades celulolíticas. De otra parte, en estudios realizados por Jahangeer (21) se demostró la actividad celulolítica de Rhizopus en medio con CMC y en un ensayo de papel filtro.

\section{Actividad quitinolitica}

La actividad quitinolítica cualitativa fue evaluada en medio mínimo con $2 \%$ de quitina coloidal. La actividad fue considerada positiva, por la capaci- 
dad del hongo de crecer en este medio, determinando diámetros o áreas de crecimiento en $\mathrm{cm} 2$. Sin embargo, solo se consideran significativas las que tuvieron un diámetro de crecimiento igual o mayor al control de la cepa de Beauveria sp.

Los hongos con crecimiento similar al control fueron la cepa Conidiobolus sp (C11), Fusarium sp, (C14), Penicillium sp (C21), Penicillium sp (C27) y Fusarium sp (C29). Mostraron su capacidad de utilizar la quitina como fuente de carbono debido a la producción de las enzimas que degradan este polímero (quitinasas). Los resultados encontrados se evidencian en la Gráfica 2.

Se observa que todos los hongos con actividad quitinolítica representativa fueron aislados de la finca Cerezo.

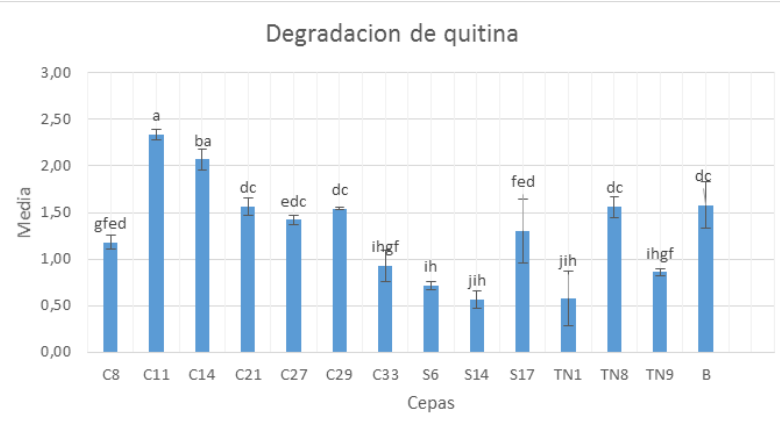

Gráfica 2. Degradación de quitina coloidal en medio mínimo, en el eje Y se observa el diámetro de hidrolisis en medio mínimo con quitina coloidal, en el eje X se observan las cepas, el control Beauveria (B) y el fitopatógeno $R$. solani (RS).

Conidiobolus sp es un hongo conocido como patógeno de insectos, principalmente las especies $\mathrm{C}$. villosus, C. coronatus, C. lamprauges y C. nanodes las cuales son conocidas por poseer hidrolasas extracelulares como quitinasas, proteasas y lipasas las cuales facilitan la penetración y la patogenicidad de este agente fúngico contra insectos y otros hongos. En estudios realizados por Ishikawa, se demostró que las especies con actividad quitinasa más potente fueron $\mathrm{C}$. lamprauges y $\mathrm{C}$. nanodes. Conidiobolus sp se ha convertido en la actualidad en un importante agente biocontrolador gracias a su alta actividad quitinolítica. $(22,23)$.
Por otro lado, en estudios realizados por Nuero y Mathivanan, se afirma que Fusarium oxysporum, F. subglutinans, F. moniliforme y F. chlamydosporum son los mejores productores de actividad quitinasa, estimulando la producción de estas enzimas usando quitina coloidal (fuente de carbono) y nitrato de sodio (fuente de nitrógeno). Esto sugiere que una alta variedad de especies de Fusarium posee un alto potencial quitinolítico, aunque este hongo ha sido mayormente descrito como fitopatógeno, se podrían continuar realizando estudios que involucren a Fusarium como un posible biocontrolador $(24,25)$.

Diversas especies de Aspergillus y Penicillium han sido aisladas de suelos ricos en quitina de campos de secado de camarón, como lo describe Patidar. Quince cepas de Aspergillus flavus, seis cepas de Aspergillus niger y dos cepas de Penicillium chrysogenum, estas últimas poseen una alta actividad quitinolítica. Esta capacidad quitinolítica fue además estudiada por Binoda, en catorce cepas de Penicillium sp usando un medio mixto con salvado de trigo y quitina para la producción de quitinasa extracelular. La mejor cepa productora de quitinasas fue Penicillium aculeatum NRRL 2129 (ATCC 10409), con un tiempo de producción de $72 \mathrm{~h}$. $(26,27)$

\section{Análisis fisicoquímico de las muestras de suelo, en relación con los hongos aislados}

Las 3 muestras de cada finca (El Cerezo, Tapias Negras y Sibaté) fueron sometidas a valoración fisicoquímica (resultados no mostrados). Los análisis fueron realizados en el laboratorio de suelos de la facultad de Ciencias Agrarias de la Universidad Nacional de Colombia. Utilizando los métodos turbidimétricos, potenciométricos, volumétricos, colorimétricos, de conductividad, densidad y absorción atómica.

Según los resultados obtenidos del análisis físicoquímico del suelo, el $\mathrm{pH}$ para las tres fincas es ácido, de acuerdo a la clasificación de la acidez en suelo, pero se encuentran en un rango 4 a 6 lo cual 
es óptimo ya que un $\mathrm{pH}$ alto perjudica el desarrollo de los hongos por la solubilidad de los metales y a $\mathrm{pH}$ bajos se afectan los sistemas enzimáticos, el ingreso de vitaminas esenciales, ácidos orgánicos y la toma de minerales. $(7,28,29)$ Estos valores de $\mathrm{pH}$, son congruentes para la producción de enzimas extracelulares que permita la sobrevivencia del hongo, respecto a la toma de nutrientes y a la competencia frente a otros microorganismos. Se conoce que la mayoría de las celulasas tienen actividades en $\mathrm{pH} 4-7$.

La finca Cerezo la cual presentó el mayor número de aislamientos contó con un valor de $\mathrm{P}, \mathrm{Ca}$ y $\mathrm{S}$ menor a las otras dos fincas.

En la finca Sibaté donde se obtuvo el menor número de aislamientos se evidenció un valor de zinc elevado de $6,67 \mathrm{mg} / \mathrm{kg}$ de suelo, comparado con 0,70 y 1,29 de Tapias Negras y Cerezos respectivamente. El $\mathrm{Zn}$ no solo es micronutriente esencial para las plantas, ya que es necesario para el funcionamiento de muchas proteínas y hormonas de crecimiento vegetal, sino también para muchas enzimas de los microrganismos.

Los valores para $\mathrm{CO}$ en las fincas están por encima del valor ideal, lo que podría reflejar restos de materia vegetal en estos suelos de pos cosecha, con características de suelos fértiles, lo que podría reflejar la presencia de varias especies de microrganismos como los hongos, ya que estos son los principales degradadores de la materia orgánica en el suelo, participando en el ciclo del carbono. (30)

En las muestras de las fincas El Cerezo y Sibaté se observan altas concentraciones de fósforo disponible, las cuales podrían estar asociadas a la cantidad de materia orgánica presente. Debe existir una relación $\mathrm{P} / \mathrm{Zn}$ ideal en suelo, valores por encima de 12 definen deficiencia de $\mathrm{Zn}$, lo que indicaría deficiencia de $\mathrm{Zn}$ en las tres fincas evaluadas. Estos datos podrían sugerir un suministro extra de fósforo al suelo por parte de los agricultores, con el fin de mejorar sus rendimientos, pero que podrían tener efectos negativos, respecto a otros micro elementos que son esenciales para los microorganismos y la misma planta (31).

Los altos niveles de fósforo pueden inhibir la infección de las plantas, en estudios realizados por Pérez, estudiaron la esporulación y colonización de micorrizas asociados al pasto angletón en función a factores físico-químico de los suelos de fincas ganaderas del municipio de Tolú-Colombia. Las fincas presentan altos porcentajes de colonización cuando se dan contenidos moderados de Fósforo y Nitrógeno (32).

\section{Antagonismo}

La prueba de antagonismo se realizó con los 37 hongos filamentosos aislados de las tres fincas, frente al hongo fitopatógeno R. solani. Los ensayos se llevaron a cabo en cajas de Petri de $90 \mathrm{~mm}$ de diámetro conteniendo PDA como medio de cultivo.

Conidiobolus sp presentó las actividades celulolítica y quitinolítica más altas que las otras cepas; sin embargo, no generó un efecto antagónico representativo frente a R. solani, posiblemente pueda deberse a mecanismos de resistencia del patógeno o la interacción de diferentes sustancias producidas por los hongos.

En estudios realizados por López se demostró la capacidad biocontroladora de Conidiobolus coronatus, Fusarium solani y Fusarium oxysporum, frente a larvas de Gallería mellonella, donde mostraron entre 16 a 100\% de biocontrol, por lo que las cepas aisladas en el presente estudio pueden ser evaluadas para el biocontrol de insectos plaga (33). 
Porcentaje de inhibicion micelial frente a Rhizoctonia solani

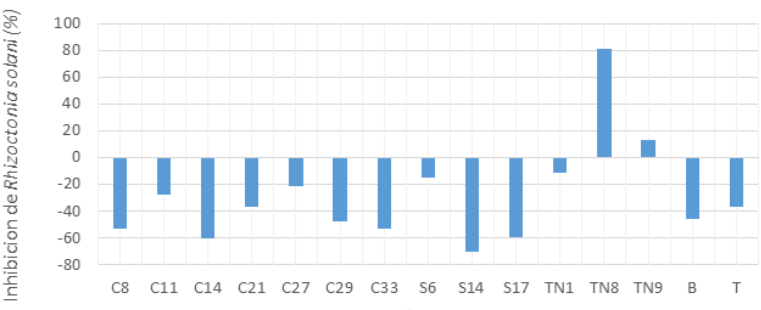

Cepas

Gráfica 3. Porcentaje de inhibición micelial de las cepas estudiadas frente a Rhizoctonia solani. En el eje Y se observa el porcentaje de inhibición micelial de las cepas frente a Rhizoctonia solani, en el eje $\mathrm{X}$ las cepas, los controles y el patógeno.

Los resultados de la Gráfica 3, demuestran que la mayoría de las cepas evaluadas, no presentaron un efecto antagónico positivo frente a $\mathrm{R}$. solani a diferencia de la cepa TN8 (Rhizopus sp), que, si evidenció efecto antagónico representativo, al inhibir en un $81,09 \%$ el crecimiento de R. solani. Según los criterios de Alber se considera antagónico si el porcentaje de inhibición micelial está entre $70 \%$ a $100 \%(5)$.

Estas cepas podrían ser consideradas para estudios complementarios y considerarlos como potenciales agentes de biocontrol. Las cepas restantes presentaron porcentajes de inhibición negativos o muy bajos debido a que generaron un sinergismo en el crecimiento de Rhizoctonia solani.

En estudios realizados por Ulacio se confrontó R. solani con diferentes hongos aislados de rizósfera de papa, a los 7 días se observó $100 \%$ de biocontrol por parte de T. harzianum, 60\% por Aspergillus flavus y no se observó antagonismo por Penicillium sp, sin embargo, este último, retrasó el crecimiento de R. solani. (6) En el presente estudio Aspergillus (TN1) no presentó antagonismo frente a Rhizoctonia solani, lo cual difiere de los estudios realizados, posiblemente debido a que su crecimiento en quitina fue muy escaso, lo cual está directamente relacionado con la baja producción de quitinasas, que serían importantes para el biocontrol, Penicillium sp no presento antagonismo frente a R. solani, datos que coinciden con los reportados por Ulacio (6).

En estudios realizados por Quiroz-Sarmiento, se evaluó la capacidad antagónica de Aspergillus frente a los hongos fitopatógenos de ajo Fusarium y Penicillium, donde se evidenciaba enrollamiento de las hifas del hongo antagónico frente al patógeno, sin embargo no existen muchos estudios sobre antagonismo de Aspergillus frente a fitopatógenos ya que se da mayor énfasis en los efectos dañinos que puede causar en los seres humanos porque producen aflatoxinas que causan intoxicación al ser ingeridos en los alimentos. Sin embargo, se han realizado estudios con cepas de Aspergillus no productoras de aflatoxinas en maíz dando mejores resultados que los que si producen aflatoxinas. En estudios realizados por Moreno en 2013 se demostró que Aspergillus giganteus produce una proteína antifúngica la cual inhibe el crecimiento y germinación de conidios de Botrytis cinérea y en el caso de Aspergillus brasiliensis, este disminuye los efectos de hongos de la podredumbre en la zanahoria. (3) (34)

Según Zhou, Conidiobolus oscuras es capaz de inducir una alta tasa de mortalidad en pulgones de bambú lo cual lo convierte en un biocontrolador eficaz. Por otra parte, Witolda, determinó que la capacidad biocontroladora de Conidiobolus coronatus se debe a un complejo de enzimas lipolíticas y quitinolíticas capaces de degradar la cutícula de los insectos y provoca parálisis en este. En el presente estudio la cepa C11 (Conidiobolus sp) mostró la más alta actividad quitinolítica (véase en la gráfica 2), lo cual demuestra que Conidiobolus sp posee un alto potencial para degradar la quitina, sin embargo en el estudio su capacidad antagónica no fue representativa (35-39).

\section{Conclusiones}

La mayoría de cepas aisladas en este estudio presentaron actividad quitinolítica y celulolítica representativa, sin embargo la cepa TN 8 (Rhizopus 
sp) fue la única cepa capaz de biocontrolar efectivamente a Rhizoctonia solani en cultivos de papa, porque la cepa TN 9 muestra muy poca acción que no es de tener en cuenta, lo cual puede retribuirse a la producción de metabolitos volátiles y/o difusos por parte de R. solani los cuales posiblemente evitaron que fuera biocontrolada.

\section{Agradecimientos}

Agradecemos a la Universidad Colegio Mayor de Cundinamarca y a la Universidad Antonio Nariño, instituciones de educación superior que aportaron los espacios y los equipos requeridos para el desarrollo de este proyecto.

\section{Referencias}

1. FEDEPAPA y Gobernación de Cundinamarca. Plagas y enfermedades dela papa [Internet]. 2010. Available from: http://jovenesrurales.minagricultura.gov.co/documents/10180/160303/ Plagas+y+enfermedades+de+la+papa-Investigaci\%C3\%B3n/0a3abf4d-a4db-4be2-ae50-d86db3c8d2ec;jsessionid=716D53C76BD55622D15676D2C62230CB.worker1

2. Finagro. Sector papero se prepara para aumentar el consumo de papa en Colombia [Internet]. 2015. Available from: https://www.finagro.com.co/noticias/sector-papero-se-prepara-para-aumentar-el-consumo-de-papa-en-colombia

3. Quiroz-Castaneda RE, Balcazar-Lopez E, Dantan-Gonzalez E, Martinez a, Folch-Mallol J, Anaya CM. Characterization of cellulolytic activities of Bjerkandera adusta and Pycnoporus sanguineus on solid wheat straw medium. Electron J Biotechnol. 2009;12(4):-

4. Teather RM, Wood PJ. Use of Congo red-polysaccharide interactions in enumeration and characterization of cellulolytic bacteria from the bovine rumen. Appl Environ Microbiol. 1982;43(4):777-80.

5. Rojas JA, Hormaza A. Evaluación del crecimiento y compatibilidad de hongos de la podredumbre blanca. Rev Cienc en Desarro. 2014;5(2):197-205.

6. Ulacio D, Salas J, Querales P, Sanabria ME. Microbiota del suelo de zonas produtoras de papa Del Estado Mérida Y Su Relación con Rhizoctonia solani. Bioagro. 2002;14(1):11-6.

7. Arias Cifuentes EL, Piñeros Espinosa PA. Aislamiento e identificacion de hongos filamentosos de muestras de suelo de los paramos de Guasca y Cruz verde. Vol. 1, Statewide Agricultural Land Use Baseline 2015. PONTIFICIA UNIVERSIDAD JAVERIANA; 2008.

8. Mayea, Novo, Valiño. Introduccion a la microbiología del suelo. 1991 ;
9. Fernández L, Rojas N, Roldán T, Ramírez M, Zegarra H, Uribe $\mathrm{R}$, et al. Manual de técnicas de análisis de suelos aplicadas a la remediación de sitios contaminados. México, D.F.: Instituto Mexicano del Petróleo y el Instituto Nacional de Ecología; 2006. 19-89 p.

10. López Rivera R. Biodiversidad de la microbiota rizosferica de dos especies solanáceas : ( Solanum lycopersicon, L .) y Datura spp . ( tomate y toloache. Instituto Politecnico Nacional; 2011.

11. Vieira FCS, Nahas E. Comparison of microbial numbers in soils by using various culture media and temperatures. Microbiol Res. 2005;160(2):197-202.

12. Pérez C. Variación intraespecífica del hongo Conidiobolus coranatus y su relación endosimbiótica con la bacteria Pseudomonas sp. Colegio de Postgraduados; 2010.

13. Castelleti E. Poblaciones epífitas de Geotrichum candidum Link ex Pers. En postcosecha de duraznos y validación de un sistema de pronóstico temprano de la pudrición en post cosecha de duraznos y validación de un sistema de pronóstico temprano de la pudrición ácida. 2010.

14. Enrique J, Latinoamericana T, Rodríguez-vázquez R, Luis R. Bacterias y hongos hidrocarbonoclastas de rizósfera de frijol y maiz en un suelo contaminado con petróleo Hydrocarbonoclastic Bacteria and Fungi of the Rhizosphere of Bean and Corn, in a Soil with Petroleum Pollution. Terra. 2003;

15. Saenz Rodriguez MN. Evaluacion del papel de los microorganismos lignoceluloliticos sobre los residuos vegetales en suelos rizosfericos de papa criolla Solanum phureja en municipios de Cundinamarca [Internet]. 2009. Available from: http://www. bdigital.unal.edu.co/8468/

16. Giraldo-Castrillón M, Torres-Gonzáles C, Díaz-Ortiz JE. Aislamiento de hongos celulolíticos causantes del biodeterioro de la Biblioteca Central de la Universidad del Valle (Cali-Colombia). Rev Mex Mic. 2009;29(April 2008):9-14.

17. Valencia M. Caracterización enzimática de cepas de Fusarium aisladas de lesiones de animales, humanos y plantas. 2009.

18. Manjares K, Piñeros Y, Rodriguez-Sandoval E. Evaluación del complejo enzimático producido mediante el cocultivo de Aspergillus sp. Y Trichoderma sp. en fase sólida sobre residuos de palma. Bioagro. 2011;23(1):19-26.

19. Cruz N, Castellanos D, Arguello H. Degradation of cellulose and xylan by microorganisms isolated in two different compost from agricultural wastes in the Bogota Plateau. Rev Colomb Ciencias Hortícolas [Internet]. 2009;3(2):237-49. Available from: http://scholar.google.com/scholar?hl=en\&btnG=Search\&q=intitle:Degradaci? $n+d e+c e l u l o s a+y+x i l a n o+p o r+m i-$ croorganismos+aislados+de+dos+tipos+de+compost+de+residuos+agr?colas+en+la+Sabana+de+Bogot?\#0

20. Escobar Escobar N, Mora Delgado J, Romero Jola NJ. Identificación De Poblaciones Microbianas En Compost De Residuos Orgánicos De Fincas Cafeteras De Cundinamarca. Boletín Científico Cent Museos Mus Hist Nat. 2012;16(1):75-88.

21. Jahangeer S, Khan N, Jahangeer S, Sohail M, Shahzad S, Ahmad A, et al. Screening and characterization of fungal cellula- 
ses isolated from the native environmental source. Pakistan J Bot. 2005;37(3):739-48.

22. Ishikawa F, Oishi K, Aida K. Chitin-binding hemagglutinin produced by Conidiobolus strains. Appl Environ Microbiol. 1979;37(6):1110-2.

23. Ishikawa F, Oishi K, Aida K. Chitinase Production by Conidiobolus lamprauges and Other Conidiobolus Species. Agric Biol Chem [Internet]. 2014;45(10):2361-2. Available from: http://www.tandfonline.com/doi/full/10.1080/00021369.19 81.10864888

24. Nuero O. Production of chitinase by Fusarium species. Curr Microbiol. 1995;30(5):287-9.

25. Mathivanan N, Kandasamy M, Kabilan V. Production of chitinase by Fusarium chlamydosporum, a mycoparasite to groundnut rust, Puccinia arachidis. Indian J Exp Biol. 1997;35(8):890-3.

26. Patidar P, Agrawal D, Banerjee T, Patil S. Optimization of process parameters for chitinase production by soil isolates of Penicillium chrysogenum under solid substrate fermentation. Process Biochem. 2005;40(9):2962-7.

27. Binoda P, Pusztahelyib T, Nagyc V, Sandhyaa C, Szakácsc G, Pócsib I, et al. Production and purification of extracellular chitinases from Penicillium aculeatum NRRL 2129 under solid-state fermentation. Enzyme Microb Technol. 2005;36(7):880-7.

28. Kavanagh K. Fungi biology and applications. 2005. 267 p.

29. Diemer M. Microclimatic Convergence of High-Elevation Tropical Páramo and Temperate-Zone Alpine Environments Title. J Veg Sci. 1996;6(821-830).

30. Tiessen H, Moir JO. Soil sampling and methods of analysis. In: Martin C, editor. Total and organic carbon. Canadian Society of Soil Science; 1993. p. 187-99.

31. Mala volta E, Paulo S. Relacion entre el fosforo y el zinc. Inf Agron. (63):12-3.

32. Perez CA, Rojas SJ, Montes V. D. Hongos formadores de micorrizas arbusculares: una alternativa biologica para la sostenibilidad de los agroecosistemas de praderas en el caribe colombiano. Rev Colomb Cienc Anim. 2011;3(2):366-85.

33. Da Silva López R. Patogenicidade de Paecilomyces farinosus sobre Coptotermes gestroi e parâmetros biológicos. Universidad Federal de Pernambuco Centro de Ciencias Biológicas. 2007.

34. Moreno Gonçalves AB. Aplicaciones biotecnológicas del gen "afp" (Antifungical Protein) de "Aspergillus giganteus" para la protección de plantas frente a infección por patógenos. Universitat de Barcelona; 2013.

35. Zhou X, Wang D-W, Zhang X, Wang J-H. The influence of the aphid-specific pathogen Conidiobolus obscurus (Entomophthoromycota: Entomophthorales) on the mortality and fecundity of bamboo aphids. J For Res. 2014;19(Issue 4):388-94.

36. Witolda E. Characterization of proteo-, chitino- and lipolytic enzymes of parasitic fungus Conidiobolus coronatus. Wiad Parazytol. 2010;56:70-83.

37. Acero-Mondragón Edward Javier, Botero Rosas Daniel Alfonso, Maldonado Arango María Inés. Micosis por Pythium Insidiosum primer caso con diagnóstico definitivo en Colombia. Nova [Internet]. 2013 Jan [cited 2017 Aug 02] ; 11( 19 ): 65-72. Available from: http://www.scielo.org.co/scielo. php?script=sci_arttext\&pid=S1794-24702013000100007\&l$\mathrm{ng}=\mathrm{en}$.

38. De Navia SLÁ, Torres SME. Calidad sanitaria del agua del Parque Natural Chicaque. Nova. 2013;11(20).

39. Rodríguez, O. E., Andrade, W. A., Díaz, F. E., \& Moncada, B. Actividad antimicrobiana de líquenes de la cuenca alta del rio Bogotá. 2015; Nova, 13(23). 